\title{
História
}

\section{Entrevista com o professor Lino de Macedo}

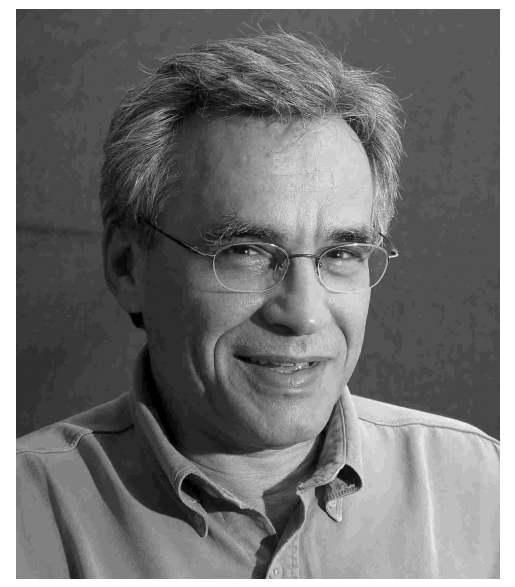

Entrevistadora: MarileneProença RebellodeSouza

LINO DE MACEDO é Professor Titular na área de Psicologia do Desenvolvimento e Doutor em Psicologia pela Universidade de São Paulo, instituição em que desenvolveu sua carreira docente, no Instituto de Psicologia. Um dos maiores estudiosos da Teoria de Piaget no Brasil, o Prof. Lino é unanimidade quando se trata de pensar, problematizar e discutir temas educacionais. Sua atuação acadêmica tem sido marcada pela presença como professor, em níveis de Graduação e Pós-Graduação, orientador e pesquisador em regime de dedicação exclusiva. No plano institucional, sua participação tem sido atuante, quer na Universidade de São Paulo, onde assumiu a Direção do Instituto de Psicologia, gestão 1997-2000, quer em entidades que fomentam o ensino e a pesquisa como a ANPEPP, exercendo a função de presidente na gestão que ora se findou. Coordena o Laboratório de Psicopedagogia do Instituto de Psicologia da USP. Orientou mais de cinquienta teses de doutorado ou dissertações de mestrado. Várias de suas publicações são referências para educadores e psicólogos, destacando-se o livro Ensaios Construtivistas, pela Casa do Psicólogo Editora. Publicou, além disso, mais de vinte capítulos em livros e mais de trinta artigos em revistas nacionais e internacionais, assim como diversos trabalhos em anais de congressos. É diretor da coleção: "Psicologia e Educação", editada pela Casa do Psicólogo. É especialista na teoria de Piaget aplicada à Psicologia ou Educação. Seu atual programa de pesquisas, no Laboratório de Psicopedagogia, é sobre o uso educacional de jogos em uma visão construtivista. É com grande orgulho que participa da seção História da revista Psicologia Escolar e Educacional, brindando-nos com suas reflexões sobre a área.

Marilene: Lino, como se deu sua aproximação com a área de Psicologia Escolar e Educacional?

Lino de Macedo: Bom, penso que essa aproximação se deu por diferentes fatores. Cito alguns deles. Nasci (1944, Frutal, MG) dentro de uma escola. Meu pai dava aulas e minha mãe cuidava da pensão para os alunos, em geral filhos de fazendeiros e sitiantes. Fiz a escola normal e, com 18 anos, já era professor de alunos das primeiras séries de uma escola rural. Fiz o curso 
de Pedagogia (1963 - 1966) e recém-formado passei a dar aulas de Psicologia de Desenvolvimento nesta mesma faculdade. Desde 1970, sou professor desta disciplina na USP (primeiro em Ribeirão Preto e, a partir de 1976, no Instituto de Psicologia, em São Paulo) considerando suas aplicações à perspectiva da aprendizagem escolar de crianças e adolescentes.

Em síntese, posso dizer que, em toda minha vida, a questão escolar, principalmente em sua relação com a Psicologia do Desenvolvimento foi uma constante. Nos últimos vinte anos tenho sido procurado por professores, sobretudo da educação básica, para dar cursos e palestras sobre o desenvolvimento da criança, segundo Piaget, e a importância disso para sua aprendizagem escolar.

Minha tese de doutorado (1973) refere-se a um trabalho experimental sobre as relações entre desenvolvimento operatório e aprendizagem. Finalmente, desde 1988 coordeno um laboratório onde os jogos são usados como recurso para a promoção dos processos de desenvolvimento das crianças em favor de sua aprendizagem escolar.

\section{Marilene: Que aspectos você destacaria como mais marcantes em sua formação para a compreensão educativa da prática psicológica?}

Lino de Macedo: Como mencionado nas respostas à questão anterior, os aspectos mais marcantes de minha visão são de natureza interdisciplinar. Ou seja, de um lado a criança e seu processo de desenvolvimento (tal como entendido e estudado experimentalmente por Piaget) e, de outro, a escola e sua função de iniciar os alunos nas artes e nas ciências, sobretudo em matemática e em língua portuguesa. Trata-se, portanto, de uma visão interdisciplinar e psicopedagógica do conhecimento. Interdisciplinar, porque disciplinas, discípulos e docentes são considerados como partes interdependentes, isto é, irredutíveis, complementares e indissociáveis. Psicopedagógica, porque a didática (os conteúdos e os modos de ensinar, bem como as características daqueles que se responsabilizam por sua transmissão) é considerada em relação (ou seja, tanto quanto possível de forma não-dualística) às crianças que aprendem e aos contextos socioculturais (família, classe social, etc.) a que pertencem e que definem, em parceria com a escola, as significações desta aquisição para elas.
Marilene: Lino, que contribuições você considera que Piaget tem trazido para a Psicologia Escolar e Educacional?

Lino de Macedo: Para mim, sua contribuição é fundamental, necessária, ainda que insuficiente e incompleta para dar conta da complexidade desta questão. Enumero algumas das contribuições de Piaget:

- Análise teórica e experimental dos processos de tomada de consciência, abstração, generalização, construção de possíveis e necessários, correspondências e transformações, implicações, lógica das significações e formas elementares da dialética. Todos esses temas foram estudados na perspectiva do sujeito que conhece, no caso crianças, com idade, aproximadamente, entre 5 e 15 anos, entrevistadas em uma dada situação experimental.

- Descrição dos níveis ou estádios de desenvolvimento das crianças em relação a temas fundamentais à sua compreensão e realização de problemas da lógica e da matemática, como, por exemplo, classificar, ordenar, quantificar, inferir, excluir variáveis, comparar, anular, compensar, estabelecer relações, deduzir, etc.

- Descrição dos níveis ou estádios de desenvolvimento da função simbólica na criança (imagem, imitação, jogo, representação, linguagem, etc.).

- Análise das formas pelas quais as crianças aprendem pouco a pouco a cooperar, trocar pontos de vista, descentrar, relacionar-se segundo regras, superar sua visão simpática ou antipática em favor da reciprocidade e da vontade como regulação social e afetiva das trocas interindividuais.

Ora, esses temas são fundamentais tanto para o professor como para o aluno.

Piaget e colaboradores fizeram muitos estudos experimentais sobre noções e operações da lógica e da matemática na criança. Disse na criança e não da criança. Por que saber isso é necessário ao processo educacional? As disciplinas escolares ensinam ainda hoje os conteúdos (conceitos e operações) pautados na perspectiva dos adultos, isto é, do conhecimento científico tal como estabelecido, demonstrado, pelos pesquisadores. A didática tradicional, neste sentido, consistia em apenas um esforço de simplificar e organizar os conceitos de modo didático e em propor exercícios e problemas que, em princípio, facilitariam a aprendizagem das crianças. Em outras palavras, uma boa 
explicação do professor deveria corresponder a uma boa compreensão das crianças, comprovada pela correção dos exercícios e das respostas certas. A retenção e a exclusão escolar, como sabemos, eram as conseqüências para aqueles que não se encaixavam neste modelo.

Ora, graças aos estudos de Piaget pôde-se provar geneticamente como as noções e operações são construídas ou reconstruídas pouco a pouco na perspectiva das crianças.

Marilene: Você tem se preocupado em buscar possíveis aproximações da teoria de Piaget com o processo educativo, com a prática em sala de aula, como você analisa tais possibilidades?

Lino de Macedo: Penso que há uma correspondência entre os interesses teóricos de Piaget e os objetivos da prática em sala de aula. Para ambos, o tornar-se é a questão mais importante. No caso da escola, como a criança torna-se alfabetizada? Como aprende noções de cálculo? No caso de Piaget, como a criança torna-se operatória, cooperativa, sensível a uma interação pautada por regras e projetos?

No meu caso, especificamente, o propósito sempre foi o de saber compartilhar o processo construtivo de meus orientandos em favor de sua formação pósgraduada. Em outras palavras, como um aluno tornase mestre e doutor? Como produz uma pesquisa, escreve uma tese? Não se trata de ser construtivista (no sentido ideológico), mas de aprender a observar e a favorecer um processo de construção. Onde está uma tese que ainda não foi escrita? Onde está a alfabetização de um aluno ainda ignorante da leitura e da escrita? O interessante da idéia de construção que na maior parte das vezes refere-se a uma reconstrução - resume-se ao problema do como criar o que não existe (caso, por exemplo, da tese) ou de transpor o que existe em um plano ou escala (já temos ciências da linguagem, os professores já sabem ler e escrever) para um outro (tornar o aluno alfabetizado). O que é construção como processo revela-se, pouco a pouco, como descoberta daquilo que já é conhecido no plano social, por exemplo. O que é construção se expressa, na prática, como invenção de estratégias ou recursos para aprender. Mas construir não se reduz de imediato a inventar ou a descobrir. Em outras palavras, os objetivos da escola coincidem, correspondem, aos interesses de Piaget, ainda que este não tenha uma contribuição específica para a aprendizagem escolar.

O fato é que, na prática, na maior parte de meu trabalho de pesquisa na pós-graduação e de relação com professores da educação básica, esta questão é a mais insistente: como se beneficiar do trabalho de Piaget em favor de uma melhor formação dos professores ou em favor de uma melhor aprendizagem escolar das crianças?

Marilene: Em alguns de seus escritos, comparece uma concepção de Psicopedagogia que difere daquela defendida pelos psicopedagogos. Como você define esta área de conhecimento?

Lino de Macedo: Como mencionado, vejo a Psicopedagogia, sobretudo, como uma forma de conceber o conhecimento. Trata-se, como disse, de uma visão interdisciplinar, relacional ou dialética, não-dualista.

Como sabemos, por aproximadamente trinta anos constava no currículo de Psicologia, a Disciplina Dificuldades de Aprendizagem e Psicopedagogia. Só que, até onde sei, a ênfase era na questão das dificuldades de aprendizagem e, mesmo assim, vistas principalmente sob dois ângulos. De um lado, com ênfase nas limitações da criança, ou seja, em suas características, nível de inteligência, resistências, etc. De outro lado, uma visão crítica desta ênfase psicológica e reducionista do problema. Ou seja, tratava-se agora de estudar as dificuldades de aprendizagem como "queixa escolar" produzida por um conjunto muito mais complexo de problemas ou variáveis escolares. $\mathrm{O}$ fato é que, em uma visão ou em outra, a Psicopedagogia era sempre desconsiderada. Como manter a Psicopedagogia, como clínica escolar, restrita aos psicólogos se isso lhes é negado em sua formação graduada?

Igualmente, nos cursos de Pedagogia não raro a ênfase é dada aos aspectos didáticos do processo de ensino, criticando-se uma visão psicológica do processo educacional. Como sustentar a Psicopedagogia como uma das possibilidades de atuação do professor se isso lhes é negado em sua formação graduada?

Em síntese, no Brasil, Psicopedagogia foi sempre algo desconsiderado, como regra geral, tanto nos cursos de Psicologia como de Pedagogia. Este vazio foi pouco a pouco sendo preenchido por professores particulares, pela clínica (de Psicologia, Fonoaudiologia, Pediatria). Esta formação foi sendo dada em cursos de 
especialização e pela reivindicação de um status profissional para as pessoas, graduadas em diferentes carreiras além da de Psicologia ou Pedagogia, que cuidam dos problemas de aprendizagem, até mesmo em sua perspectiva institucional. Como defender um estatuto profissional, negando a norma que no Brasil define profissão apoiada na graduação?

Quanto a mim, a questão psicopedagógica, como mencionado, sempre me interessou, mas como área de conhecimento e na perspectiva da leitura que pude fazer das contribuições de Piaget sobre essa questão. Em outras palavras, nunca me considerei um "psicopedagogo", mas um professor de Psicologia do Desenvolvimento.

O fato é que uma visão psicopedagógica dos processos de aprendizagem e do desenvolvimento é cada vez mais importante, sem que se chegue a um acordo sobre as diferentes possibilidades de se obter ou mais que isso de se certificar essa formação. Como disse, a Psicologia reclama esse privilégio, mas na prática não sabe como fazê-lo, porque reluta em superar sua visão de aprendizagem restrita àquele que aprende ou não aprende, aos processos psicológicos ou subjetivos deste processo. Como incluir, no âmbito da Psicologia, por exemplo, os conteúdos ensinados (Matemática, Língua Portuguesa, conceitos médicos ou saúde)? Os cursos de especialização em Psicopedagogia reclamam este privilégio, esquecidos de que no Brasil uma profissão é definida pela graduação e não pela pós-graduação.

\section{Marilene: Que aspectos da obra de Piaget são} objeto de seus estudos recentes?

Lino de Macedo: Nos últimos anos dediquei-me, sobretudo, a cinco grandes temas relacionados à obra de Piaget.

Primeiro: Estou trabalhando em uma caracterização metodológica do conhecimento em construção. Para isso, propus no curso de pós-graduação em Psicologia Escolar e do Desenvolvimento Humano uma disciplina: "A pesquisa em uma visão construtivista". As aulas foram gravadas e transcritas. Tenho a esse respeito a primeira versão de um livro (180 páginas) que reúne o principal que pude trabalhar sobre esse assunto. Meu projeto é publicá-lo no próximo ano. Além disso, orientei teses e dissertações sobre temas relacionados à teoria de Piaget.
Segundo: Meu grande interesse nos últimos quinze anos é estudar a parte final da obra de Piaget. Os temas mais importantes dessa parte da obra de Piaget são: tomada de consciência, realizar e compreender, abstrair, generalizar, estabelecer correspondências e transformações, lógica das proposições, formas elementares da dialética, a construção de possíveis e necessários. Estudar esses livros, dar palestras e cursos sobre os temas neles tratados tem sido um grande desafio e alegria para mim.

Terceiro: Pude fazer uma leitura bastante cuidadosa do livro Biologia e conhecimento (Piaget, 1967).

Quarto: Publiquei, pela Editora Artmed, o livro Ensaios Pedagógicos (2004) sobre palestras que fiz nos últimos cinco anos, envolvendo a questão de pensar a escola inclusiva em uma perspectiva construtivista.

Quinto: Publiquei, com Ana Lúcia Sicoli Petty e Norimar Christe Passos, três livros (o último será lançado em 29/11) sobre nosso modo de usar jogos de regras, em um contexto de oficinas, como recurso de observação e promoção do desenvolvimento e da aprendizagem escolar de crianças da escola fundamental bem como para a formação de seus professores ou orientadores.

\section{Marilene: Que experiência profissional comparece como uma das mais marcantes para você?}

Lino de Macedo: Bom, como qualquer professor em uma universidade como a USP, o desafio é sabermos fazer de tudo um pouco, é sabermos gerir tantas tarefas e demandas, não esquecendo de nosso tema de estudo, de nossas responsabilidades para com a causa universitária, para com nossos compromissos de professor, pesquisador e divulgador do conhecimento científico em Psicologia.

Nestes trinta anos de USP fiz minha carreira universitária completa (mestrado, doutorado, livre docência, concurso de professor associado e titular), fui chefe e vice-chefe de departamento, diretor e vicediretor do Instituto de Psicologia, participei de todos os órgãos colegiados; orientei 60 teses e dissertações; dei aulas na graduação e na pós-graduação; coordenei o Laboratório de Psicopedagogia; dei palestras e cursos de extensão. Compartilhei trabalhos de muitos tipos. Fui representante da Psicologia na CAPES, fui presidente da ANPEPP (Associação Nacional de 
Pesquisa e Pós-graduação em Psicologia), sou presidente da SBPD (Sociedade Brasileira de Psicologia do Desenvolvimento). Em todas essas oportunidades aprendi e tenho podido aprender com meus colegas, com as tarefas propostas e com o projeto que anima cada uma delas. Daí minha gratidão e reconhecimento a todas as pessoas que me possibilitaram essas experiências e às boas condições que me permitiram realizá-las e a aprender com todas elas. Muito obrigado. 